\title{
Effects of Urea Supplementation On The Nutritional Quality And Microbial Community of Alfalfa (Medicago Sativa $L$.) Silage
}

\author{
Zhenping Hou \\ Chinese Academy of Agricultural Sciences https://orcid.org/0000-0001-5207-0519 \\ Xia Zheng \\ Chinese Academy of Agricultural Sciences \\ Xuelei Zhang \\ Chinese Academy of Agricultural Sciences \\ Qing Chen \\ Chinese Academy of Agricultural Sciences \\ Duanqin Wu ( $\nabla$ wuduanqin@caas.cn ) \\ Chinese Academy of Agricultural Sciences
}

\section{Research Article}

Keywords: urea, Medicago sativa L, nutrient composition, microbial diversity

Posted Date: December 21st, 2021

DOI: https://doi.org/10.21203/rs.3.rs-1136310/v1

License: (1) This work is licensed under a Creative Commons Attribution 4.0 International License. Read Full License 


\section{Abstract}

The objectives of this study were to evaluate the contribution of urea on the nutritional quality and microbial community of ensiled alfalfa (Medicago sativa L.). Alfalfa silage was control group without urea (AL), supplementation with $0.5 \%$ urea (AU1), or supplementation with $1 \%$ urea (AU2). The silage tanks were opened and sampled after silage at $0,15,30$, and $60 \mathrm{~d}$. Results showed that $\mathrm{AU} 2$ had higher $\mathrm{pH}$, ratio of $\mathrm{NH}_{3}-\mathrm{N} / \mathrm{TN}$ and $\mathrm{CP}$ content than those in $\mathrm{AL}$ and $\mathrm{AU} 1$ while AU1 had higher ADF than that in AL and AU2 after $15 \mathrm{~d}$ silage. Richness and diversity indices of microbial communities in silage were no significant differences among AL, AU1 and AU2 group. Proteobacteria (58.23\%) and Firmicutes (40.95\%) were the predominant phylum in three groups during the silage process. The percent of community abundances on genera level of Enterobacteriaceae $(37.61 \%)$ and Klebsiella $(41.78 \%)$ in AL were a little higher than those in AU1 $(30.39 \%, 25.02 \%)$ and AU2 $(33.48 \%, 26.92 \%)$. These results showed that silage with urea alone could not improve the quality of alfalfa.

\section{Introduction}

Alfalfa (Medicago sativa L.), which plays a very important role in agriculture, animal husbandry, and ecological construction, is an excellent perennial legume forage because of its extensive ecological adaptability, high nutrition value, palatability, and biological nitrogen fixation (Wang et al. 2016). Owing to its high protein content, it provides excellent pasture for ruminants and, universally, it is utilized in the form of green alfalfa feed for grazing or as hay or pellets (Putnam et al. 2014). However, alfalfa green hay is seasonal, so silage has become an effective means of utilization of alfalfa. However, it is very difficult to produce high quality alfalfa silage because of its low water-soluble carbohydrates and high buffering capacity.

In practice, silage additives are usually added to improve the fermentation quality of alfalfa silage. At present, the commonly used silage additives include lactic acid bacteria, green juice fermentation, formic acid, glucose, urea, etc. (McDonald et al, 1991). Adequate addition of lactic acid bacteria can ensure the number of lactic acid bacteria needed in the initial stage of silage fermentation and promote lactic acid fermentation. Urea is commonly used as a feed additive to improve the quantity of nitrogen content and ruminant digestibility (Joy et al. 1992; Sindt et al. 1994; Hosammani et al. 1998). During silage, proper addition of urea can improve the crude protein content, nutritional value and preserve the soluble carbohydrates in silage materials. To date, little information is available on the single application of urea in forage silage, and whether urea have positive effects on promoting the fermentation quality of alfalfa silage is not clear.

Thus, the objective of this study was to investigate the effects of urea supplementation on the nutritional quality and microbial community of alfalfa silage.

\section{Materials And Methods}

\subsection{Harvesting and Silage}

Alfalfa (Medicago sativa L.) from the Hunan Province, China, was harvested at the initial flowering stage, leaving stubble of $5 \mathrm{~cm}$ with a forage harvester. The harvested alfalfa was chopped to about $2.0 \mathrm{~cm}$ in length using a straw chopper after it was wilted until DM to 65 $\%$ on the plot. After wilting, alfalfa was silage with/without urea in a special plastic storage tank (plastic drums of $5 \mathrm{dm}^{3}$ each, diameter $17.5 \mathrm{~cm}$, and height $28.3 \mathrm{~cm}$ ). Urea was prepared on the day of silage, applied in powder at $0 \%$ (AL), $0.5 \%$ (AU1) and $1 \%$ (AU2) of the fresh weight, respectively. Before being packed into the tanks, urea was spread on the chopped forage on the floor and thoroughly mixed. Approximately $2 \mathrm{~kg}$ of chopped fresh alfalfa was immediately packed into a special plastic storage tank, compacted, sealed with plastic wraps (internally and externally), and stored at $20^{\circ} \mathrm{C}-25^{\circ} \mathrm{C}$ until sampled. There were 36 silage tanks in each treatment.

\subsection{Chemical Analysis}

After silage for $0,15,30$, and $60 \mathrm{~d}$, the silage tanks were opened and samples were taken for chemical analysis with three replicates for each treatment. In total, 36 samples were collected.

Silage samples ( $20 \mathrm{~g}$ each) were diluted with $180 \mathrm{~mL}$ of distilled water, homogenized for $1 \mathrm{~min}$ in an Erlenmeyer flask to obtain silage alfalfa extracts, filtered through two layers of cheesecloth, and immediately analyzed for pH using a digital pH meter (Model PH S210Basic, METTLER TOLEDO Solutions, Shanghai Precision \& Scientific Instrument Co., LTD, China). 
An aliquot of the silage alfalfa extract was centrifuged at $12,000 \times \mathrm{g}$ for 10 min at $4{ }^{\circ} \mathrm{C}$ (Weatherburn, 1967). Taking $15 \mu \mathrm{L}$ supernatant added to $300 \mu \mathrm{L}$ phenol-Nitpuna solution in a $1.5 \mathrm{ml}$ centrifuge tube, mix well, then add $300 \mu \mathrm{L}$ base sodium hypochlorite solution to mix well again and incubated at $37^{\circ} \mathrm{C}$ for $30 \mathrm{~min}$. The supernatant was analyzed for ammonia-N using a microplate reader (TACAN, Switzerland) set at $625 \mathrm{~nm}$. The percentage of total nitrogen was calculated using Eq. 1:

$$
\text { Total nitrogen }(\%)=\frac{\text { crude protein }(C P) \text { \% }}{6.25}(\text { Eq. 1) }
$$

Five hundred grams silage were dried in the air-blower-driver drying closets at $65^{\circ} \mathrm{C}$ for $48 \mathrm{~h}$ and used for further chemical analysis. Dry matter (DM), crude protein (CP), crude fiber (CF), neutral detergent fiber (NDF), acid detergent fiber (ADF), in the silage were analyzed according to the methods of the Association of Official Analytical Chemists (AOAC) (William and George, 2007).

\subsection{Total Deoxyribonucleic Acid Extraction, Polymerase Chain Reaction Amplification and 16S Ribosomal Ribonucleic Acid Sequencing}

Total DNA was extracted using the E.Z.N.A. ®Stool DNA Kit (D4015, Omega, Inc., Norcross, GA, USA) according to manufacturer's instructions. After DNA isolation, the purity and concentration of genomic DNA were measured with a spectrophotometer (Nanodrop 115 1000, Thermo Fisher Scientific, Waltham, MA, USA) and its integrity was verified by agarose ( $0.8 \%)$ gel electrophoresis. After being eluted in Elution buffer, the total DNA was stored at $-80^{\circ} \mathrm{C}$ until measurement in the polymerase chain reaction (PCR).

Polymerase chain reaction amplification was performed in a total volume of $25 \mu \mathrm{L}$ of reaction mixture containing $25 \mathrm{ng}$ of template DNA, 12.5 $\mu \mathrm{L}$ PCR Premix, $2.5 \mu \mathrm{L}$ of each primer, and PCR-grade water to adjust the volume. The V3-V4 region of the bacteria 16S rRNA gene was amplified with primers 338F (5'-ACTCCTACGGGAGGCAGCAG-3') and 806R (5'-GGACTACHVGGGTWTCTAAT-3') by thermocycler PCR system (GeneAmp 9700, ABI Inc., Edison, NJ, USA). The PCR conditions for the amplification of the prokaryotic $16 \mathrm{~S}$ fragments consisted of an initial denaturation at $98^{\circ} \mathrm{C}$ for $5 \mathrm{~min} ; 35 \mathrm{cycles}$ of $10 \mathrm{~s}$ for denaturation at $98{ }^{\circ} \mathrm{C}, 30 \mathrm{~s}$ for annealing at $54^{\circ} \mathrm{C}$, $45 \mathrm{~s}$ for extension at $72{ }^{\circ} \mathrm{C}$; and a final extension at $72{ }^{\circ} \mathrm{C}$ for $10 \mathrm{~min}$. The PCR products were confirmed through $2 \%$ agarose gel electrophoresis. Then, the PCR products were extracted from the agarose gel, purified by AMPure XT beads (Beckman Coulter Genomics, Danvers, MA, United States), and quantified by Qubit (Invitrogen, Carlsbad, CA, USA) according to the manufacturer's protocol. The amplicon pools were used for sequencing. The size of amplicon library was assessed on the Agilent 2100 Bioanalyzer (Agilent, Santa Clara, CA, USA), while the number was evaluated using the Library Quantification for Illumina (Kapa Biosciences, Woburn, MA, USA). Finally, the Phix Control library (V3, Illumina, Inc., San Diego, CA, USA) was unified with the amplicon library (expected at $30 \%$ ).

\subsection{Sequence Processing and Bioinformatics Analysis}

The amplicon sequences were conducted using an Illumina MiSeq platform according to the manufacturer's recommendations, provided by LC-Bio (LC-Bio, Hangzhou, Zhejiang, China). All paired-end reads were merged using FLASH (version 2.1.11, Magoč and Salzberg, 2011). Quality filtering on the raw tags was performed according to the FQTRIM (V 0.94) to obtain the high-quality clean tags. Low-quality sequences were filtered out using Vsearch software (v2.3.4, Rognes et al. 2016). The same operational taxonomic units (OTUs) were assigned by Vsearch (v2.3.4), with $\geq 97 \%$ sequence similarity. The Ribosomal Database Project (RDP) classifier was applied to perform sequence-level taxonomic assignment. Alpha diversity was applied in analyzing the complexity of species diversity for a sample through five indices, including Chao1, observed species, Good's coverage, Shannon, and Simpson's diversity induces, and these were calculated in our samples using QIIME (Version 1.8.0). Beta diversity analysis was used to evaluate the differences in the samples in terms of species complexity. Beta diversity was calculated by principal coordinate's analysis (PCoA) and cluster analysis using the QIIME software (Version 1.8.0).

\subsection{Statistical Analysis}

The experiment was a completely randomized design with three treatments, three replicates, and four-time points per treatment. The model included the treatment $(\mathrm{T})$ effect, silage time (ST) effect, and the treatment $\times$ silage time $(\mathrm{T} * \mathrm{ST})$ reaction effect. The nutrient data were analyzed by the general linear model (GLM) procedure of SAS (version 8.0; SAS Institute, Inc., Cary, NC, USA), and the means were separated. Tukey-Kramer multiple comparison test was used for the different sample means. Differences among means were considered significant at $P<0.05$ and extremely significant at $P<0.01$, whereas $0.05 \leq P<0.1$ was considered as a tendency of significant difference. The SAS and R (v3.0.3) software were used for analyzing the 16S rRNA gene data. Continuous variables such as number of reads, the relative abundance of bacteria, and species richness and diversity were analyzed using the GLM procedure of SAS. 
After statistical comparison of the taxa, Benjamini-Hochberg correction was used to control the false discovery rate by the package "p.adjust" in R; $P<0.05$ was considered as statistically significant.

\section{Results}

\subsection{Effects of Urea on the Nutritional Quality of Alfalfa Silage}

The nutritional qualities of alfalfa before and after silage are shown in Table 1. The addition of urea to alfalfa led to a higher silage $\mathrm{pH}$ compared with that of AL. T and ST significantly affected the pH value. As urea concentration increased (from 0 to $1 \%$ ) in the same ST, the $\mathrm{pH}$ value of silage alfalfa increased gradually $(P<0.001)$. However, with the prolongation of ST ( 0 to $\mathrm{d} 60)$ in the same T, the $\mathrm{pH}$ value decreased significantly to some extent $(P<0.001)$.Meanwhile, the observed $\mathrm{T}{ }^{\star} \mathrm{ST}$ had no significant effect on the $\mathrm{pH}$ value. The T and ST did not affect $(P>0.05) \mathrm{DM}$, and no interactions between T*ST were observed for DM. After silage started, $\mathrm{CP}$ of alfalfa silage decreased significantly $(P<0.001)$ with the increase of urea content. With the extension of $\mathrm{ST}$ in the same group, $\mathrm{CP}$ significantly decreased $(P<0.001)$. Significant interaction of $T \star S T$ was observed for $\mathrm{CP}$ content $(P=0.000)$. The effect of urea was curvilinear, with a decrease $(P \otimes 0.05)$ on $\mathrm{CF}$ in $\mathrm{AU} 1$ and AU2 groups. ST significantly influenced CF $(P<0.01)$, but there were no regular changes with the ST extension. The ST significantly affected NDF $(P<0.01)$ in AL, except for those of AU1 and AU2 groups. The T and interaction of $\mathrm{T} * \mathrm{ST}$ had no significant effect on NDF. Higher ADF contents on average were observed in the alfalfa silage of AU1 and AU2 groups as compared to that of $\mathrm{AL}$ group $(P<0.01)$. With the increase of $S T$, ADF contents decreased linearly and significantly $(P<$ 0.001). The $T \star S T$ on had no significant effect on ADF. The $\mathrm{NH}_{3}-\mathrm{N} / \mathrm{TN}$ ratio in AU2 group was significantly higher than that in $A L$ group $(P<0.001)$. At the beginning of silage, the $\mathrm{NH}_{3}-\mathrm{N} / \mathrm{TN}$ ratios of silage in all groups were higher $(P<0.001)$ than those in the other ST. With the increase of urea addition, the ratio of $\mathrm{NH}_{3}-\mathrm{N} / \mathrm{TN}$ in silage increased linearly and significantly $(P<0.001)$. The effects of ST on the ratio of $\mathrm{NH}_{3}-\mathrm{N} / \mathrm{TN}$ were significantly positive $(P<0.001)$, except on the first day of silage. There was a significant effect in the interaction of $\mathrm{T} * \mathrm{ST}$ on the $\mathrm{NH}_{3}-\mathrm{N} / \mathrm{TN}$ ratio $(P<0.001)$.

\subsection{Alpha and Beta Diversity Analysis in the Alfalfa Silage}

This study used high throughput analyses targeting variable regions 3 and 4 of $16 \mathrm{~S}$ rDNA to detect the bacterial diversity of alfalfa silage. There were three treatments and four time points per treatment. After removing unqualified sequences, the valid sequences in the three groups were 12287, 33216, and 33350 on d 0; 16949, 27089, and 30804 on d 15; 16056, 35886, and 29050 on d 30; and 18453, 32933, and 29527 on d 60, respectively (BioProject ID: PRJNA743588). In the valid high-quality sequences, the sequences between 400500 bp, 300-400 bp, and 200-300 bp were $94.63 \%, 3.85 \%$, and $1.07 \%$, respectively, and the other sequences had less than 200 bp (Fig. 1). The Good's coverage for all the samples was more than $97 \%$, which meant that the sequencing data was reliable (Fig. 2), and these reads were clustered into 622 (7464) OTUs based on a $97 \%$ sequence identity (equal to the species level). According to the taxonomy analysis, there were 11 phyla, 19 classes, 36 orders, 80 families, 165 genera, and 332 species in total.

Alpha diversity and beta diversity characterized the dynamics of the full microbiome. The richness and diversity indices of microbial communities in alfalfa silage were evaluated based on their alpha diversity (Table 2). AU1 and AU2 groups had higher OTU levels than that of AL group $(P<0.01)$. In AU1 and AU2 groups, T*ST significantly affected OTU level $(P<0.05)$. The T and ST did not affect $(P \square$ $0.05)$ Chao1 index, but T*ST had significant effect on AU1 and AU2 groups $(P<0.05)$. No significant effects were observed on the Observed species, Shannon and Simpson's diversity indices $(P>0.05)$.

Beta diversity analysis of microbiota in silage was visualized using a principal coordinate analysis (PCoA) plot based on UniFrac (unweighted) distances (Fig. 3).The result of PCoA revealed compositional differences in the bacterial community of 20 samples. These showed the bacterial community structures of samples from all silage were gathered relatively. Silage samples of AU1_15 and AU1_60 were separated from the AL and AU2 samples, which suggested that proper addition of urea had an impact on microbial community. But distinctions among bacterial communities in all silage were not very clear.

\subsection{Microbial Community Analysis}

The main microbial communities in silage are shown in Flig. 4. Fig. 4A represents the microbial community composition of silage in 11 phyla. Proteobacteria (58.23\%) was the most predominant phylum and Firmicutes (40.95\%) was the second most dominant phylum in the silage process. With the extension of ST, the relative abundance of Proteobacteria in AL, AU1 and AU2 group increased to $67.63 \%, 79.16 \%$, and $73.48 \%$, respectively. However, the relative abundance of Firmicutes in AL, AU1 and AU2 group decreased to $31.28 \%, 20.18 \%$, and $26.09 \%$ for all silages, respectively. 
To further understand the effect of urea supplementation on microbial community, the relative abundance of bacterial community on genus level is exhibited in Fig. 4B. During silage, the average dominant bacteria were Enterobacteriaceae (33.83 \%), Klebsiella (31.24 \%), and Weissella (10.81\%) in all groups. As ST lengthened, the relative abundance of these bacteria showed irregular changes in all groups. The average relative abundances of Enterobacteriaceae (37.61\%) and Klebsiella (41.78 \%) in the AL group were a little higher than those in AU1 $(30.39 \%, 25.02 \%)$ and AU2 $(33.48 \%, 26.92 \%)$ group.

\section{Discussion}

\subsection{Nutritional quality of alfalfa silage}

Research showed that the lower $\mathrm{pH}$ value, the less ammonia- $\mathrm{N}$ content, the easier the silage, the better quality of silage (Mceniry et al. 2007). In this experiment, the pH value of alfalfa silage in AL group at $d 60$ was the lowest among all silages, but it ranked inferiorly when its $\mathrm{pH}$ value was 5.37 ( $\mathrm{Liu}, 2004)$. Under these experimental conditions, silages were inferior. Similar to the findings of Pancholy et al (1994), urea, as an additive to silage made from tropical forages, decreased fermentation quality by increasing silage $\mathrm{pH}$ value. Alfalfa has high protein content, but a low soluble carbohydrate and DM content (McDonald et al. 1991); thus, it is hard to produce sufficient lactic acid to lower the $\mathrm{pH}$ value. The urea addition did not increase the contents of those two substances, so the $\mathrm{pH}$ value of silage alfalfa in the present study was very high (Table 1). The ratio of $\mathrm{NH}_{3}-\mathrm{N} / \mathrm{TN}$ reflects the degree of protein and amino acid decomposition in silage. The higher ratio indicates more protein breakdown and poor silage quality. In this experiment, the ratio of $\mathrm{NH}_{3}$ N/TN increased significantly with the increase in urea addition and extension of ST. There were consistent with the results of some researchers (Yunus et al. 2001), which showed that addition urea in silage could significantly increase pH value and ratio of volatile basic nitrogen (VBN)/TN of silages without supplementation of other silage additives. Researchers found that adding urea to sorghum silage could significantly increase the content of $\mathrm{CP}$ and lactic acid and improve the application value of sorghum silage (Wu et al. 2007). This was because the use of urea additives could make up for the shortage of $\mathrm{N}$ in sorghum silage.

To evaluate the nutritional quality of alfalfa silage, several conventional nutritional indices were tested in this study (Table 1). Liu et al (2010) reported that adding urea could increase the DM content of silage. Researches (Moosa et al. 2012; Zhao et al. 2016) showed that urea supplementation could reduce NDF and ADF in silage and increase CP. This study indicated that $T, S T$, and T*ST did not affect the DM content of alfalfa silage; meanwhile, all factors had significant negative effects on CP. ADF is negatively correlated with animal's digestibility, which means the lower ADF, the higher digestibility and the greater feeding value of forage (Kung et al. 2003).Our results showed that ST significantly influenced CF and ADF, but the influences were irregular. Numerically, the CF and NDF contents of alfalfa silage in AU1 and AU2 groups were higher than those in AL group, but the differences were not significant among groups. With the increase of urea addition and ST, ADF increased significantly. These results were different from those of the other researchers (Martins et al. 2015; Zhao et al. 2016), who found that adding urea in forage could significantly decrease NDF and ADF. This may be due to different silage materials.

Liu et al (2002) found that CP of rice straw increased by $10.3 \%$ after urea treatment. Our results showed that $\mathrm{NH}_{3}-\mathrm{N} / \mathrm{TN}$ ratio in silage gradually increased with the increase of urea addition, and the ratio in AU2 group was significantly higher than that of AL group. This result was consistent with that the higher the $\mathrm{NH}_{3}-\mathrm{N} / \mathrm{TN}$ ratio, the lower the $\mathrm{CP}$, and the worse the silage quality. The present results were contrary to those of Liu et al (2002), which may be due to the different amount of urea and raw materials.

\subsection{Microbial quality evaluation of alfalfa silage}

From the results, the average Good's coverage for all samples was $98 \%$, which indicated that the depth of sequencing was adequate for reliable analysis of the bacterial community. During silage process, changes of alfalfa silage environment were reflected by the slight decrease in the Chao1 index due to the formation of the acidic and anaerobic microenvironment. The microbial diversities and richness of $A U 1$ and AU2 groups were higher than those of AL group because of urea addition. After urea addition, microorganisms could use these non-proteins $\mathrm{N}$ to synthesize bacterial proteins, which increase microbial reproduction, resulting in microbial diversity increased. This was consistent with the results of some researchers (Mendez-Garcia et al. 2015), who found that low pH was the main factor underlying limited microbial diversity.

Normally, ensiling is a microbial based and anaerobic fermentation process dominated by lactic acid bacteria (LAB), which converts water soluble carbohydrates (WSC) into organic acids, mainly lactic acid, resulting in the decline of $\mathrm{pH}$ and inhibition of undesirable microorganisms (Dunière et al. 2013; Eikmeyer et al. 2013). Ni et al (2017) found that the microbial community in terminal silage could 
not be predicted by that of fresh material because large numbers of epiphytic non-LAB bacteria species in pre-ensiled were suppressed or inactivated in the following silage process. From our results, AU1 and AU2 groups had similar microbial communities, which differed from those of $A L$ group. This indicated that the addition of urea could markedly affect the bacterial community composition of alfalfa silage regardless of supplemental level. The variation in microbial community might be an important indicator for efficient fermentation of alfalfa silage after adding urea.

Pang et al (2011) reported that most of bacterial community in silage belonged to the phylum Firmicutes and the genera Lactobacillus, Pedicoccus, and Weissella. This study results showed that the dominant phyla in the measured samples were Proteobacteria and Firmicutes. With the increase of urea addition and the extension of ST, the number of Proteobacteria decreased relatively, while that of Firmicutes increased relatively. The relative abundance of Firmicutes in AU1 and AU2 groups at 15th day (43.64 \% and $44.97 \%$, respectively) were greater $(P<0.05)$ than that of $\mathrm{AL}(5.24 \%)$ group, however Proteobacteria in the alfalfa silage of AU1 and AU2 (55.11 $\%$ and $54.63 \%$ ) groups, respectively, were lower than that of AL (93.14\%) group. Though this change was not obvious on day 30 and 60 of silage, the relative abundance of Firmicutes in AU1 and AU2 groups were higher, and Proteobacteria in AU1 and AU2 groups were kept lower compared to that of AL group. This result was similar with that of McGarvey et al (2013), who found a shift in the bacterial community from Proteobacteria to Firmicutes, with the relative abundance of Proteobacteria reduced from $89.6 \%$ to $26.9 \%$, whereas that of Firmicutes increased from $8.1 \%$ to $70.6 \%$ after $40 \mathrm{~d}$ silage. Allen et al (2009) found that the abundance of the dominant phyla was greater and that of microbial community was less. Similar to the results of other researchers (Allen et al. 2009; McGarvey et al. 2013), urea addition led to a higher abundance of Proteobacteria and Firmicutes in silage, which resulted in the relatively simple microbial diversity.

From the current results, the prevalent genera (Fig.5B) in all silages were Enterobacteriaceae, Klebsiella, and Weissella. This result was different from that of other researchers (Pang et al. 2011; Ni et al. 2018), who found that most bacteria involved in lactic acid fermentation of silage belonged to genera Lactobacillus, Pedicoccus, Weissella, and Leuconostoc. Pediococcus usually grows vigorously and initiate lactic acid fermentation at the early stage of ensiling, thereby stimulating the dominance of Lactobacillus species; while Lactobacillus become more active and grow vigorously as the $\mathrm{pH}$ drops. However, in the present study, the relative abundance of Enterobacteriaceae and Klebsiella decreased with the urea addition increase. The relative abundance of Weissella, Lactobacillus, and Pediococcus increased in AU1 and AU2 groups. Researchers (Lin et al. 1992) found that P. pentosaceus was the dominant LAB at the early stage of fermentation, while Lactobacillus dominated within the community after $7 \mathrm{~d}$ of silage. In general, after anaerobic fermentation, the complex microbial communities of the raw materials are gradually replaced by LAB, which is one of the criteria for successful silage (Mcdonald et al. 1991). Therefore, the microbial diversity would sharply reduce after successful fermentation. In our study, although microbial diversity decreased with silage, it did not decrease with the urea addition increase. The higher relative abundance of Enterobacteriaceae and Klebsiella and the lower relative abundance of Pediococcus and Lactobacillus may be relative to the postponed formation of acidic environment. These results were consistent with the pH value (Table 1), which might explain the unsuccessful silage in the present study.

\section{Conclusions}

This study has shown that, after adding urea to alfalfa silage, the $\mathrm{pH}$ value, CF content, and DM loss of silage did not decrease, while the $\mathrm{CP}$ content, abundance and diversity of beneficial bacteria did not increase with the increase of urea addition and silage time. These results indicate silage with urea alone does not improve alfalfa quality.

\section{Declarations}

\section{Acknowledgments}

This study was financially supported by Chinese Academy of Agricultural Sciences and Central Public-interest Scientific Institution Basal Research Fund (No.1610242021005), Natural Science Foundation of Hunan Province (2021JJ50028), Agricultural Science and Technology Innovation Project Special Fund of Chinese Academy of Agricultural Sciences (ASTIP-IBFC). We thank all present and past members of Wu laboratory who have contributed comments and ideas.

\section{Statements of Animal Rights}

The experimental protocol in this study was approved by the Institute of Bast Fiber Crops, Chinese Academy of Agricultural Sciences (No.20190519), Hunan province, China. The authors confirm that all studies have performed in accordance with the ethical standards 
laid down in the 1964 Declaration of Helsinki and its later amendments.

\section{Conflict of Interest Statement}

The authors declare no conflict of interest.

\section{References}

1. Allen, B., Kon, M., Bar-Yam, Y. 2009.A new phylogenetic diversity measure generalizing the Shannon index and its application to phyllostomid bats, American Naturalist, 174, 236-243. https://doi.org/10.1086/600101

2. Dunière, L., Sindou, J., Chaucheyras-Durand, F., Chevallier,I., Thévenot-Sergentet,D. 2013. Silage processing and strategies to prevent persistence of undesirable microorganisms, Animal Feed Science and Technology, 182, 1-15. https://doi.org/10.1016/j.anifeedsci.2013.04.006

3. Eikmeyer, F.G., Köfinger, P., Poschenel, A., Jünemann, S., Zakrzewski, M., Heinl, S., Mayrhuber, E.,Grabherr, R.,Pühler,A.,Schwab, H. 2013. Metagenome analyses reveal the influence of the inoculant Lactobacillus buchneri CD034 on the microbial community involved in grass ensiling, Journal Biotechnology, 167, 334-343. http://dx.doi.org/10.1016/j.anifeedsci.2013.04.006

4. Hosammani, S.V., Mehra, U.R., Dass, R.S. 1998.Effect of different planes of nutrition on urea molasses mineral block intake, nutrient utilization, rumen fermentation pattern and blood profile in murrah, rumen fermentation pattern and blood profile in murrah buffaloes (Bubalus bubalis), Animal Feed Science Technology, 76, 117-128. https://doi.org/10.1016/S0377-8401(98)00202-8

5. Joy, M., Alibes, X., Munoz, F. 1992. Chemical treatment of lignocellulosic residues with urea, Animal Feed Science Technology, 38,319-333. https://doi.org/10.1016/0377-8401(92)90022-X

6. Lin, C., Bolsen, K.K., Brent, B.E., Fung, D.Y.C. 1992. Epiphytic lactic acid bacteria succession during the pre-ensiling and ensiling periods of alfalfa and maize, Journal of Applied Bacteriology, 73,375-387. https://doi.org/10.1111/j.1365-2672.1992.tb04992.x

7. Liu, C.L., Sun, F.J., Li, C.S., Sun, H.X. 2002. Effects of different treatments on nutritional value of rice straw. Journal of Yellow Cattle Science, 28(1), 28-30. https://doi.org/10.3969/j.issn.001-9111®2002『01-0028-02.2004.01.008 (in Chinese, with English abstract)

8. Liu, J.X. 2004. Processing Technology of Hay Straw Silage. Beijing: China Agricultural University Press, 180-194. (in Chinese, with English abstract)

9. Liu, J.Y., Yu, M., Wang, A.K., Huang BZ, Li RS, Zhang MQ, Sun WT. 2010.Influences of the Quality of Sugarcane Tip Silage by Adding Urea, Chinese Cattle Science, 36(4),22-25. https://doi.org/10.3969/j.issn.1001-9111.2010.04.006 (in Chinese, with English abstract)

10. Magoč, T., Salzberg, S. L.2011.FLASH: fast length adjustment of short reads to improve genome assemblies, Bioinformatics, 27(21), 2957-2963. https://doi.org/10.1093/bioinformatics/btr507

11. Martins, S.C.S.G., Carvalho, G.G.P., Pires, A.J.V., Silva, R.R., Leite, L.C., Pereira, F.M., Mota, A.D.S., Nicory, I.M.C., Cruz, C.H.da. 2015. Qualitative parameters of sugarcane silages treated with urea and calcium oxide, Semina: Ciências Agrárias, 36,1135-1144. https://doi.org/10.5433/1679-0359.2015v36n2p1135

12. McDonald, P., Henderson, A.R., Herson, S.J.E. 1991. The Biochemistry of Silage, $2^{\text {nd }}$ edition. Chalcombe publication, Marlow, UK.

13. Mceniry, J., O’Kiely, P., Clipson, N. J. W., Forristal, P.D., Doyle, E.M. 2007.The relative impacts of wilting, chopping, compaction and air infiltration on the conservation characteristics of ensiled grass, Grass Forage Science, 62(4), 470-

484. https://doi.org/10.1111/j.1365-2494.2007.00602.x

14. McGarvey, J.A., Franco, R.B., Palumbo, J.D., Hnasko, R., Stanker, L., Mitloehner, F.M. 2013.Bacterial population dynamics during the ensiling of Medicago sativa (alfalfa) and subsequent exposure to air, Journal of Applied Microbiology, 114, 16611670. https://doi.org/10.1111/jam.12179

15. Mendez-Garcia, C., Peláez, A.I., Mesa, V., Sanchez, J., Golyshina, O.V., Ferrer, M. 2015. Microbial diversity and metabolic networks in acid mine drainage habitats. Frontiers in Microbiology,6, 475. https://doi.org/10.3389/fmicb.2015.00475

16. Moosa, V., Mohsen, D.M., AliReza, V. 2012.Fermentation characteristics, in situ rumen degradation and aerobic stability of whole crop barley ensiled with urea or aqueous ammonia, American Journal of experimental Agriculture, 2(1),21-30. https://www.webofscience.com/wos/alldb/full-record/CABI:20123099856

17. Ni, K., Minh, T.T., Tu, T.T., Tsuruta, T., Pang, H., Nishino, N. 2017.Comparative microbiota assessment of wilted Italian ryegrass, whole crop corn, and wilted alfalfa silage using denaturing gradient gel electrophoresis and next-generation sequencing, Applied Microbiology Biotechnology, 101,1385-1394. https://doi.org/10.1007/s00253-016-7900-2

Page 7/12 
18. Ni, K., Zhao, J., Zhu, B., Su, R., Pan, Y., Ma, J., Zhou, G., Tao, Y.,Liu, X., Zhong, J. 2018. Assessing the fermentation quality and microbial community of the mixed silage of forage soybean with crop corn or sorghum, Bioresource Technology,265, 563-567. https://doi.org/10.1016/j.biortech.2018.05.097

19. Pancholy, R., Mali, P.C., Mathur, A. 1994. Effect of urea-molasses and lactic culture on silage fermentation of Cenchrus ciliaris, Annals of Arid Zone, 33, 147-150. https://www.webofscience.com/wos/alldb/full-record/CABI:19950712844

20. Pang, H., Qin, G., Tan, Z., Li, Z., Wang,Y., Cai, Y. 2011.Natural populations of lactic acid bacteria associated with silage fermentation as determined by phenotype, 16S ribosomal RNA and recA gene analysis, Systematic and Applied Microbiology, 34,235-241. https://doi.org/10.1016/j.syapm.2010.10.003

21. Putnam, D.H., Orloff, S.B.2014.Forage crops,Encyclopedia of Agriculture and Food Systems, 3,381-405. https://doi.org/10.1016/B978-0-444-52512-3.00142-X

22. Rognes, T., Flouri, T., Nichols, B., Quince, C., Mahé, F. 2016.VSEARCH: a versatile open source tool for 516 metagenomics, Peer Journal, 4, e2584. https://doi.org/ 10.7717/peerj.2584

23. Sindt, M, H,Stock, R. A., Klopfenstein, T. J. 1994. Urea vs. urea and escape protein for finishing calves and yearlings, Animal Feed Science Technology, 49:103-117. https://doi.org/ 10.1016/0377-8401(94)90085-X

24. Wang, D., Khurshid, M., Sun, Z.M.,Tang, Y.X., Zhou, M.L.,Wu, Y.M. 2016.Genetic Engineering of Alfalfa (Medicago sativa L.), Protein Peptide Letter, 23(5), 495-502. https://doi.org/ 10.2174/0929866523666160314152618

25. Weatherburn M.W.1967.Phenol-hypochlorite reaction for determination of ammonia, Analytical Chemistry, 39(8), 971-974 . https://doi.org/10.1021/ac60252a045

26. William, H., George, W. eds. 2007.Official Methods of Analysis of AOAC International,18th edn, AOAC International, Gaithersburg, MD.

27. Wu, J.D., Chen, Y.B., Sun, W. 2007. Influence of adding urea on the quality of silage corn straw, Journal of West Anhui University, 23(5), 87-89. https://doi.org/10.3969/j.issn.1009-9735.2007.05.027 (in Chinese, with English abstract)

28. Yunus, M., Ohba, N., Tobisa, M., Shimojo, M., Masuda, Y. 2001. Effect of glucose and formic acid on the quality of napiergrass silage after treatment with urea, Asian Australian Journal of Animal Sciences,14(2), 211-

215. https://doi.org/10.5713/ajas.2001.211

29. Zhao, L. P., Ren, L. P., Zhou, Z. M., Meng, Q. X., Hou, Y. L., Wang, F. 2016. Improving ruminal degradability and energetic values of bamboo shoot shell using chemical treatments, Animal Science Journal, 87, 896-903. https://doi.org/10.1111/asj.12512

\section{Tables}

\section{Table 1 Effects of urea on the nutritional quality of the alfalfa silage}




\begin{tabular}{|c|c|c|c|c|c|c|c|c|c|c|c|}
\hline \multirow[t]{2}{*}{ Items ${ }^{1}$} & \multirow[t]{2}{*}{ Treatments $^{2}$} & \multirow[t]{2}{*}{ Mean } & \multirow[t]{2}{*}{ SEM } & \multicolumn{4}{|c|}{ silage Time (d) } & \multirow[t]{2}{*}{ SEM $^{3}$} & \multicolumn{3}{|c|}{$p$-value ${ }^{4}$} \\
\hline & & & & 0 & 15 & 30 & 60 & & $\mathrm{~T}$ & ST & $\begin{array}{l}\text { Tx } \\
\text { ST }\end{array}$ \\
\hline \multirow[t]{3}{*}{$\mathrm{pH}$} & $\mathrm{AL}$ & $5.62^{b}$ & 0.153 & $6.12^{\mathrm{a}}$ & $5.52^{b}$ & $5.45^{\mathrm{bc}}$ & $5.37^{c}$ & 0.114 & 0.001 & $\begin{array}{l}0.001 \\
0\end{array}$ & 0.450 \\
\hline & AU1 & $6.71^{\mathrm{ab}}$ & & $7.57^{\mathrm{a}}$ & $6.66^{\mathrm{b}}$ & $6.32^{b}$ & $6.28^{\mathrm{b}}$ & & & & \\
\hline & AU2 & $7.62^{a}$ & & $8.10^{\mathrm{a}}$ & $7.65^{\mathrm{b}}$ & $7.58^{\mathrm{b}}$ & $7.16^{\mathrm{C}}$ & & & & \\
\hline \multirow[t]{3}{*}{ DM (\%) } & $\mathrm{AL}$ & 29.42 & 0.700 & 29.58 & 30.17 & 27.26 & 30.69 & 0.675 & 0.522 & 0.059 & 0.932 \\
\hline & AU1 & 29.41 & & 28.63 & 30.43 & 27.99 & 30.58 & & & & \\
\hline & AU2 & 28.66 & & 28.79 & 28.41 & 27.64 & 29.78 & & & & \\
\hline \multirow[t]{3}{*}{$\mathrm{CP}(\%)$} & $\mathrm{AL}$ & $17.19^{a}$ & 0.212 & $18.01^{a}$ & $17.46^{\mathrm{a}}$ & $16.99^{a b}$ & $16.31^{\mathrm{b}}$ & 0.201 & $\begin{array}{l}0.001 \\
0\end{array}$ & $\begin{array}{l}0.001 \\
0\end{array}$ & 0.000 \\
\hline & AU1 & $16.57^{b}$ & & $17.58^{\mathrm{a}}$ & $16.49^{b}$ & $13.99^{d}$ & $15.21^{c}$ & & & & \\
\hline & AU2 & $15.82^{b}$ & & $17.45^{\mathrm{a}}$ & $17.19^{a}$ & $16.61^{a}$ & $15.03^{b}$ & & & & \\
\hline \multirow[t]{3}{*}{$\mathrm{CF}(\%)$} & $\mathrm{AL}$ & 27.41 & 0.703 & $26.27^{b}$ & $27.17^{b}$ & $29.40^{\mathrm{a}}$ & $26.82^{b}$ & 0.579 & 0.074 & 0.002 & 0.056 \\
\hline & AU1 & 28.86 & & $30.99^{a}$ & $28.80^{a b}$ & $29.83^{a}$ & $25.82^{b}$ & & & & \\
\hline & AU2 & 28.26 & & $27.30^{\mathrm{b}}$ & $30.00^{a}$ & $30.27^{a}$ & $25.49^{b}$ & & & & \\
\hline \multirow[t]{3}{*}{ NDF (\%) } & $\mathrm{AL}$ & 43.44 & 0.818 & $46.01^{a}$ & $40.41^{b}$ & $42.79^{a}$ & $44.55^{\mathrm{ab}}$ & 0.741 & 0.278 & 0.001 & 0.163 \\
\hline & AU1 & 44.37 & & 48.11 & 41.02 & 43.92 & 44.41 & & & & \\
\hline & AU2 & 44.44 & & 46.28 & 44.51 & 44.02 & 42.94 & & & & \\
\hline \multirow[t]{3}{*}{ ADF (\%) } & $\mathrm{AL}$ & $35.42^{b}$ & 0.669 & $39.85^{a}$ & $36.73^{a}$ & $33.18^{b}$ & $31.92^{b}$ & 1.339 & 0.006 & $\begin{array}{l}0.001 \\
0\end{array}$ & 0.810 \\
\hline & AU1 & $38.19^{a}$ & & $43.65^{a}$ & $40.00^{a}$ & $35.67^{b}$ & $33.42^{b}$ & & & & \\
\hline & AU2 & $38.18^{a}$ & & $42.87^{a}$ & $39.48^{b}$ & $37.26^{b}$ & $33.10^{c}$ & & & & \\
\hline \multirow[t]{3}{*}{$\begin{array}{l}\mathrm{NH}_{3}-\mathrm{N} / \mathrm{TN} \\
(\%)\end{array}$} & $\mathrm{AL}$ & $18.02^{\mathrm{b}}$ & 0.777 & $9.25^{b}$ & $11.24^{\mathrm{b}}$ & $11.93^{b}$ & $39.63^{a}$ & $\begin{array}{l}0 . \\
522\end{array}$ & $\begin{array}{l}{[} \\
0.001\end{array}$ & $\begin{array}{l}\square \\
0.001\end{array}$ & $\begin{array}{l}\square \\
0.001\end{array}$ \\
\hline & AU1 & $22.49^{a b}$ & & $13.13^{b}$ & $17.33^{b}$ & $17.57^{b}$ & $41.93^{\mathrm{a}}$ & & & & \\
\hline & AU2 & $29.88^{a}$ & & $17.12^{b}$ & $27.10^{b}$ & $25.02^{b}$ & $41.72^{a}$ & & & & \\
\hline
\end{tabular}

${ }^{1}$ Nutrient content ;

${ }^{2} \mathrm{AL}$, control; AU1, control $+0.5 \%$ urea; $\mathrm{AU} 2$, control $+1 \%$ urea;

${ }^{3}$ SEM, standard error of means;

${ }^{4} \mathrm{~T}$, treatments; ST, silage time.

Table 2 Richness and diversity indices of microbial communities in alfalfa silage 


\begin{tabular}{|c|c|c|c|c|c|c|c|c|c|c|c|}
\hline \multirow[t]{2}{*}{ Items $^{1}$} & \multirow[t]{2}{*}{ Treatments $^{2}$} & \multirow[t]{2}{*}{ Mean } & \multirow[t]{2}{*}{ SEM } & \multicolumn{4}{|c|}{ Silage Time } & \multirow[t]{2}{*}{ SEM $^{3}$} & \multicolumn{3}{|c|}{$p$-value ${ }^{4}$} \\
\hline & & & & 0 & 15 & 30 & 60 & & $\mathrm{~T}$ & ST & $T \star S T$ \\
\hline \multirow[t]{3}{*}{ OTUs } & $\mathrm{AL}$ & $511.00^{b}$ & 72.646 & 495.00 & 541.67 & 535.67 & 471.67 & 52.233 & 0.000 & 0.835 & 0.041 \\
\hline & AU1 & $687.08^{a}$ & & $785.67^{a}$ & $550.00^{c}$ & $704.33^{b}$ & $708.33^{b}$ & & & & \\
\hline & AU2 & $621.19^{a}$ & & $451.77^{d}$ & $784.00^{a}$ & $664.67^{b}$ & $584.33^{c}$ & & & & \\
\hline \multirow[t]{3}{*}{ Chao1 } & $\mathrm{AL}$ & 733.50 & 47.450 & 828.30 & 794.09 & 718.41 & 593.20 & 94.901 & 0.855 & 0.198 & 0.005 \\
\hline & AU1 & 720.38 & & $827.16^{a}$ & $580.99^{b}$ & $750.83^{a b}$ & $722.55^{\mathrm{ab}}$ & & & & \\
\hline & AU2 & 702.46 & & $623.53^{b}$ & $867.97^{a}$ & $691.70^{\mathrm{ab}}$ & $626.64^{\mathrm{ab}}$ & & & & \\
\hline \multirow{3}{*}{$\begin{array}{l}\text { Observed } \\
\text { species }\end{array}$} & $\mathrm{AL}$ & 415.42 & 22.026 & 454.00 & 425.67 & 427.67 & 354.33 & 94.000 & 0.840 & 0.083 & 1.000 \\
\hline & AU1 & 410.50 & & 467.00 & 377.67 & 396.00 & 401.33 & & & & \\
\hline & AU2 & 405.08 & & 409.00 & 472.00 & 405.67 & 333.67 & & & & \\
\hline \multirow[t]{3}{*}{ Shannon } & $\mathrm{AL}$ & 3.76 & 0.231 & 3.91 & 3.55 & 3.62 & 3.97 & 0.461 & 0.374 & 0.190 & 0.210 \\
\hline & AU1 & 4.08 & & 4.30 & 4.38 & 3.90 & 3.75 & & & & \\
\hline & AU2 & 3.91 & & 4.30 & 4.35 & 3.54 & 3.43 & & & & \\
\hline \multirow[t]{3}{*}{ Simpson } & $\mathrm{AL}$ & $0.78^{b}$ & 0.018 & 0.78 & 0.76 & 0.77 & 0.81 & 0.035 & 0.007 & 0.833 & 0.303 \\
\hline & AU1 & $0.85^{a}$ & & 0.84 & 0.85 & 0.85 & 0.84 & & & & \\
\hline & AU2 & $0.82^{\mathrm{ab}}$ & & 0.83 & 0.87 & 0.79 & 0.80 & & & & \\
\hline
\end{tabular}

${ }^{1}$ Richeness and diversity indices of microbial communities;

${ }^{2} \mathrm{AL}$, control; AU1, control + $0.5 \%$ urea; AU2, control + $1 \%$ urea;

${ }^{3} \mathrm{SEM}$, standard error of means;

${ }^{4} \mathrm{~T}$, treatments; ST, Silage time.

\section{Figures}

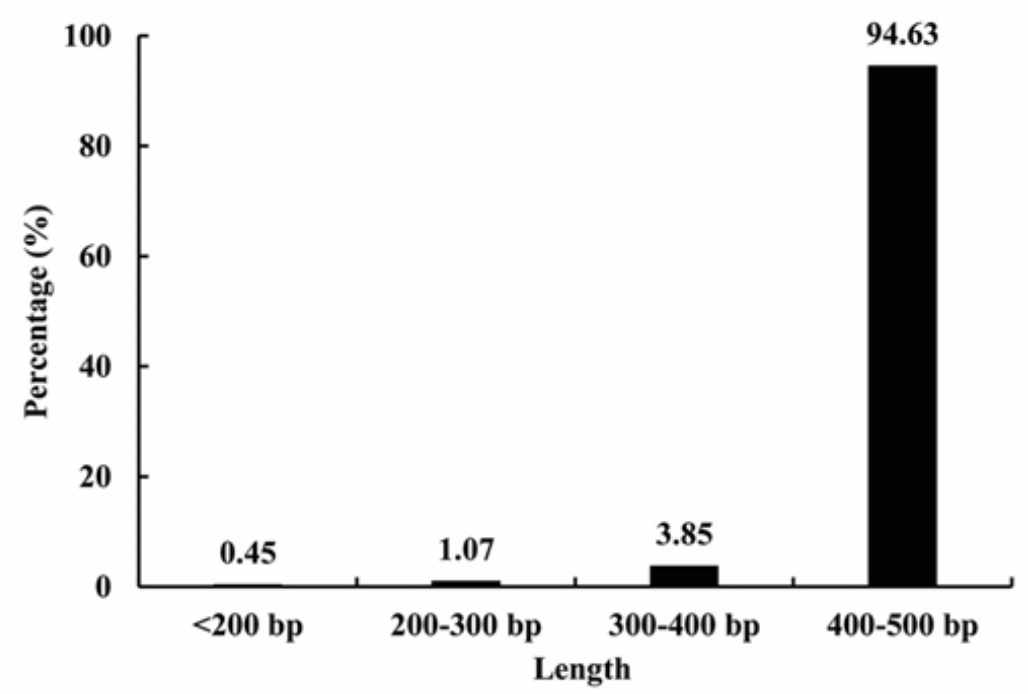

Page 10/12 
Figure 1

Percentage of valid sequences

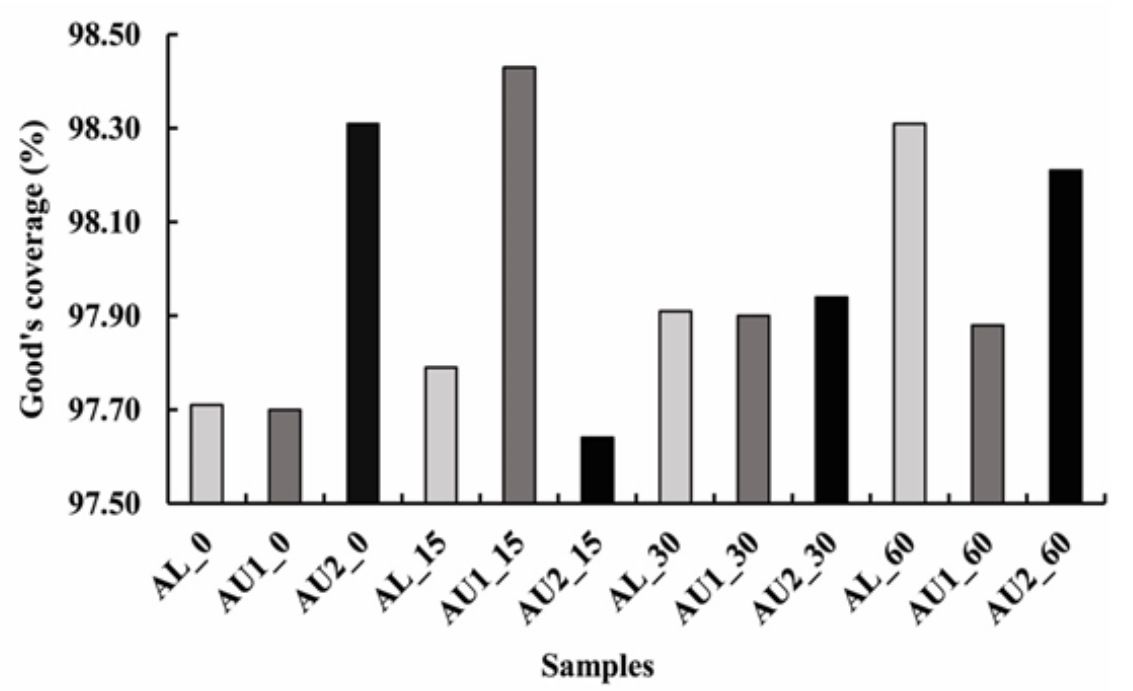

Figure 2

Good's coverage for all samples . AL, control; AU1, control $+0.5 \%$ urea; AU2, control $+1 \%$ urea; $0,15,30$, and 60 refer to silage time.

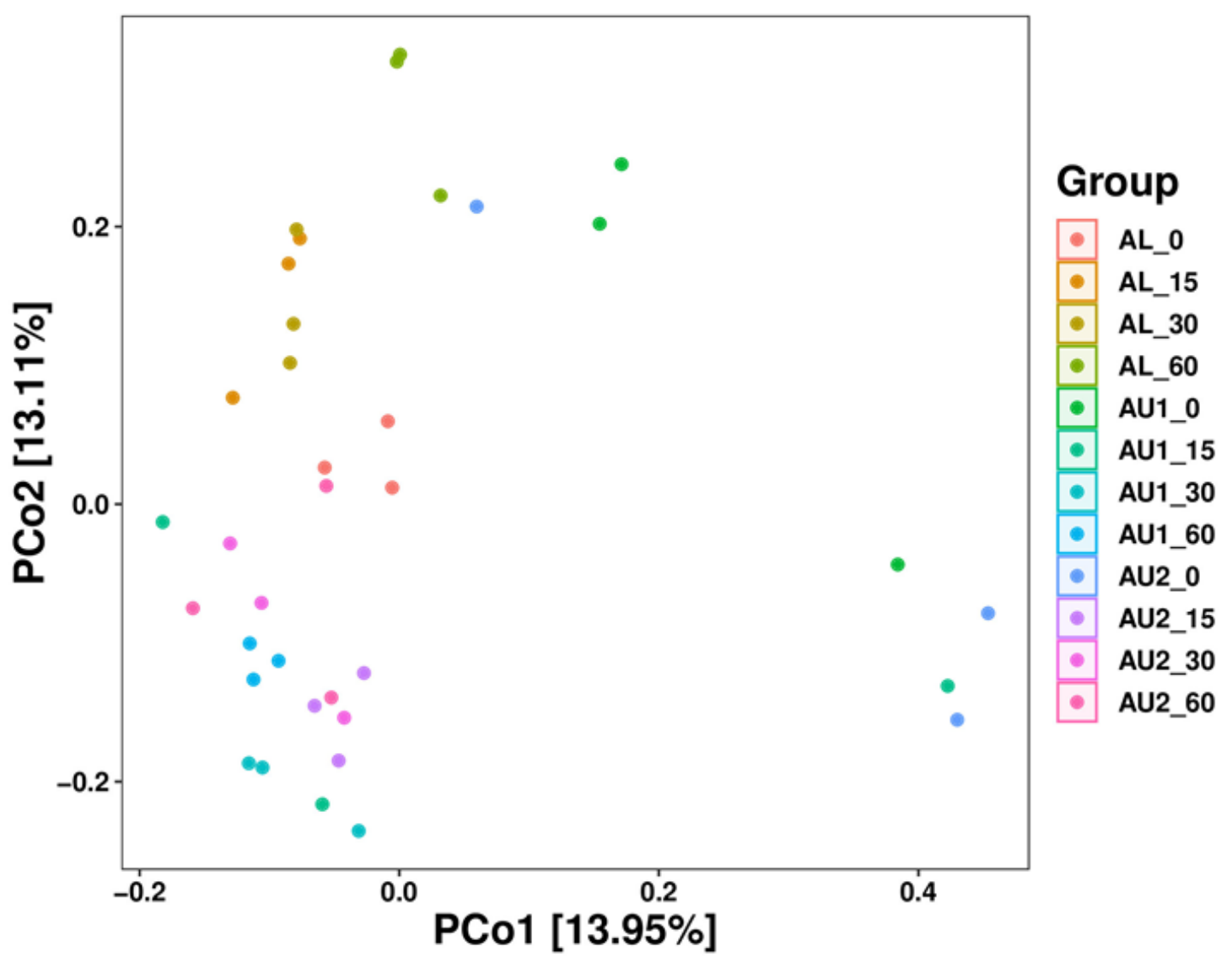

Figure 3 
Principal coordinate analysis (PCoA) of bacterial communities for alfalfa silage. AL, control; $A U 1$, control $+0.5 \%$ urea; $A U 2$, control +1 $\%$ urea; $0,15,30$, and 60 refer to silage time.
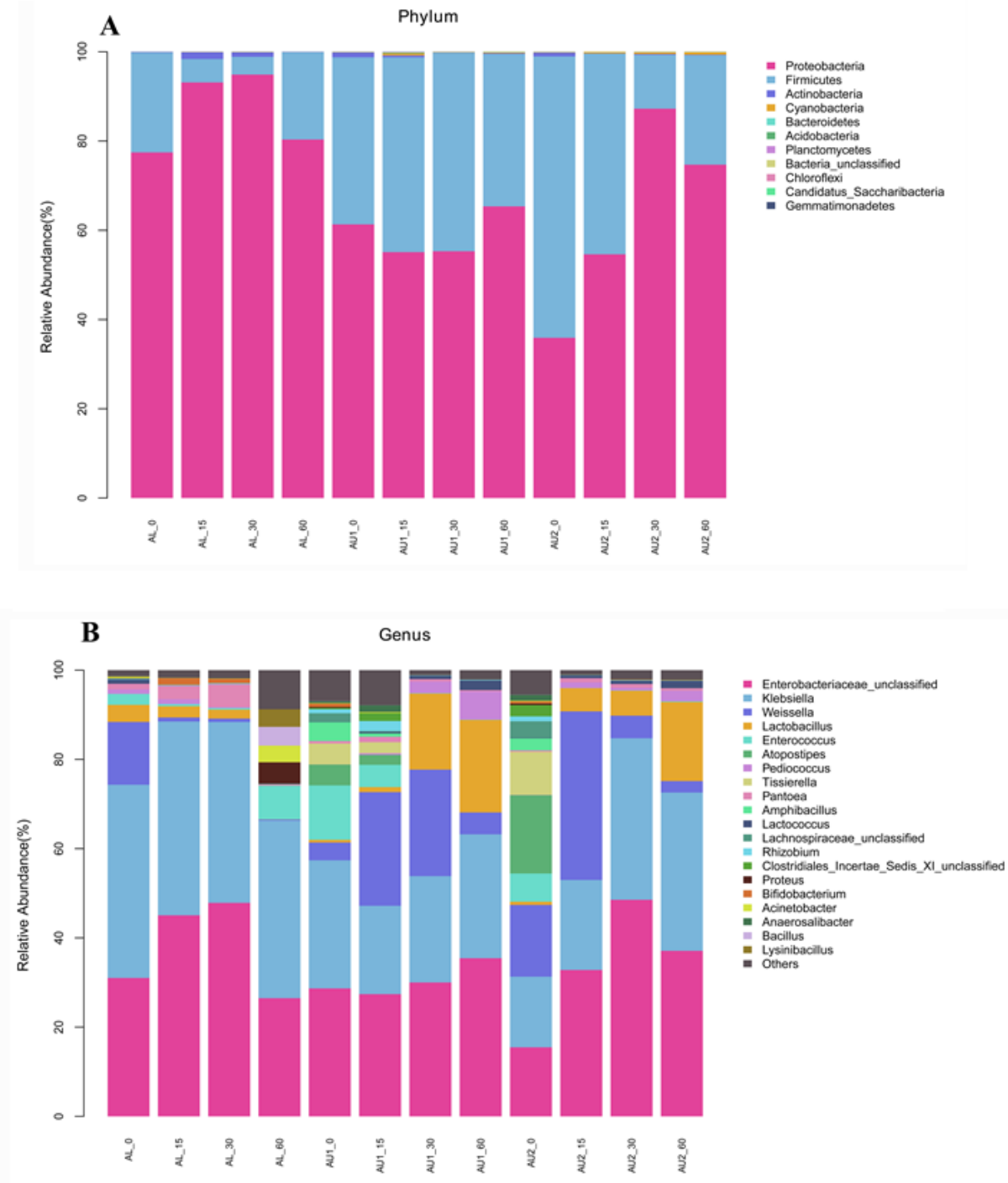

\section{Figure 4}

Bacterial community and relative abundance of phylum (A) and genus (B) for alfalfa silage. AL, control; AU1, control + $0.5 \%$ urea; AU2, control $+1 \%$ urea; $0,15,30$, and 60 refer to silage time. 